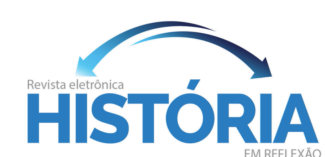

O PERFIL DOS CONSELHEIROS NA BAIXA IDADE MÉDIA IBÉRICA: O LIBRO DEL CONSEJO E DE LOS CONSEJEROS

Douglas Mota Xavier de Lima

Êmily Sthephane Rodrigues

\title{
O PERFIL DOS CONSELHEIROS NA BAIXA IDADE MÉDIA IBÉRICA: O LIBRO DEL CONSEJO E DE LOS CONSEJEROS
}

\author{
THE PROFILE OF THE COUNCILORS IN THE IBERIAN MIDDLE \\ AGES: THE LIBRO DEL CONSEJO E DE LOS CONSEJEROS
}

\author{
Douglas Mota Xavier de Lima ${ }^{1}$ \\ Êmily Sthephane Rodrigues ${ }^{2}$
}

\begin{abstract}
Resumo
Tendo em vista a crescente importância do Conselho para as monarquias medievais, este artigo propõe analisar o perfil dos conselheiros na Idade Média ibérica, a partir dos espelhos de príncipes, gênero que se afirma no Ocidente medieval desde o século XIII com origens na tradição textual greco-romana, cristã e muçulmana. Para o estudo discute-se o Libro del Consejo e de los consejeros, de Maestre Pedro, primeiro tratado conhecido na Península Ibérica destinado aos conselheiros régios. O trabalho busca demonstrar como o texto constrói um perfil dos conselheiros pautado em vícios e virtudes, criando uma pedagogia política aos homens que passavam a orientar as monarquias do período.

Palavras-chave: Espelhos de Príncipe. Conselho. Libro del Consejo e de los consejeros.
\end{abstract}

\begin{abstract}
In view of the growing importance of the Council for medieval monarchies, this article proposes to analyze the profile of the councilors in the iberian Middle Ages from the mirrors of princes, a genre affirmed in the medieval West since the thirteenth century with origins in the Greek and Roman, Christian and Muslim textual tradition. For the study it is analyzed the Libro del Consejo e de los consejeros, of Maestre Pedro, the first treaty in the Iberian Peninsula destined to the regal councilors. The work aims to show how the text builds a profile of councilors guided by virtues and vices, creating a political pedagogy for the men who passed to guide the monarchies of the period.
\end{abstract}

Keywords: Mirrors of prince. Council. Libro del Consejo e de los consejeros.

\footnotetext{
${ }^{1}$ Professor adjunto da Universidade Federal do Oeste do Pará, nas áreas de História Antiga e História Medieval. E-mail: douglas.mxl@ufopa.edu.br

${ }^{2}$ Graduanda do curso de Licenciatura em História da Universidade Federal do Oeste do Pará, bolsista PIBIC-UFOPA. E-mail: emilysthephane@gmail.com
} 


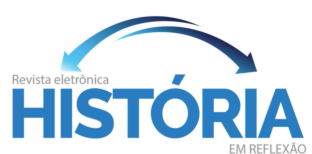

O PERFIL DOS CONSELHEIROS NA BAIXA IDADE MÉDIA IBÉRICA: O LIBRO DEL CONSEJO E DE LOS CONSEJEROS

Douglas Mota Xavier de Lima

Êmily Sthephane Rodrigues

O desenvolvimento do Conselho Régio entre os séculos XIII e XVI é uma das principais expressões das mudanças ocorridas nas monarquias ocidentais em finais do medievo, constituindo uma instância que tem como função assessorar a realeza nos assuntos legislativos, judiciários e diplomáticos. Concentrando a atenção nesse último aspecto, o presente estudo se insere numa investigação mais ampla sobre as relações entre Corte, Conselho e Diplomacia na Baixa Idade Média Ibérica que se estrutura na hipótese de que o mapeamento do perfil do conselheiro permite inferir sobre o perfil dos embaixadores do período. Parte-se do duplo pressuposto de que o embaixador de finais da Idade Média e inícios do mundo moderno é "paradigma do cortesão", com suas pautas e comportamentos ligados aos modelos elaborados no espaço da corte (VAQUERO, 2005), e que o locus sócio-político de escolha dos enviados diplomáticos na Baixa Idade Média concentra-se na corte régia, sendo os conselheiros do rei frequentemente escolhidos como embaixadores (PÉQUIGNOT, 2009; SANTOS, 2015; LIMA, 2016).

Ao fim da Idade Média se observa no Ocidente medieval um fenômeno comum que envolve o Conselho e a Diplomacia. No primeiro caso, como assinala Cédric Michon (2012), assiste-se ao processo de institucionalização dos conselhos, movimento que se manifesta na formalização de regimentos para a instância, na especialização das funções e dos conselheiros, e na preocupação crescente com as qualidades dos membros do conselho. Desse último aspecto, resulta a ampliação da produção de textos que visavam orientar os comportamentos dos conselheiros, literatura que desde o século XIV foi se afirmando como um subgênero da literatura especular e pode ser caracterizada como "espelhos de conselheiros" (MUNIZ, 2005).

Paralelamente, a escolha dos embaixadores e o papel destes como representantes de um poder em negociações diplomáticas são questões que se ampliaram nos textos da Baixa Idade Média. Exemplo dessa tendência, Ambaxiatorum Breviologus, de Bernard du Rosier, consta como o primeiro tratado acerca dos embaixadores escrito no Ocidente, contemporâneo do surgimento das embaixadas 


\section{HISTÓRIA}

O PERFIL DOS CONSELHEIROS NA BAIXA IDADE MÉDIA IBÉRICA: O LIBRO DEL CONSEJO E DE LOS CONSEJEROS

Douglas Mota Xavier de Lima

Êmily Sthephane Rodrigues

permanentes e expressão do processo de definição do ofício dos agentes participantes nas missões diplomáticas. Nesse contexto, Stéphane Péquignot (2016) demontrou como os espelhos de príncipes e outros gêneros textuais do período oferecem recomendações aos embaixadores, tratando das virtudes a serem cultivadas, dos vícios a serem evitados, dos comportamentos esperados, entre outros aspectos que buscaram orientar a ação dos enviados diplomáticos.

A época medieval assistiu à multiplicação de discursos sobre o príncipe e a realeza, assumindo destaque especial o gênero dos specula principis, uma vasta literatura de caráter político, moral e pedagógico que visava estabelecer as virtudes para o ofício régio e para o bom governo do reino (BUESCU, 1997, p. 33). Com raízes na Antiguidade Clássica, nos pais da Igreja e mesmo em tradições textuais do mundo muçulmano, ao longo do medievo tais escritos estiveram presentes na educação régia e, na Baixa Idade Média, foram utilizados como instrumentos de afirmação e legitimação das monarquias.

Ana Isabel Buescu (1997) indica que a referida multiplicação dos discursos sobre o príncipe e a realeza esteve inscrita no emergir de uma pluralidade de instâncias de legitimação do príncipe e de um poder central em construção entre os séculos XIII e XVI. Tais argumentos fundamentam-se nas proposições de Roger Chartier sobre três tipos de estratégias que favoreceram o desenvolvimento da instituição monárquica no período: a ordem do discurso, a ordem dos sinais e a ordem das cerimônias. Para o autor, a ordem do discurso pode ser compreendida a partir do texto dito ou escrito, ou seja, o discurso está para além do texto escrito, o que implica na representação do poder nas mais diversas áreas possíveis, sendo o discurso uma delas. Segundo Chartier, entre textos e imagens, entre cerimônias e discursos escritos, os laços são estreitos, convindo não os separar dos diferentes meios de expressão de comunicação através dos quais o Estado (ou aqueles que são, ou pensam ser, os seus senhores) é representado (CHARTIER, 2002, p. 227-228). 


\section{HISTÓRIA}

O PERFIL DOS CONSELHEIROS NA BAIXA IDADE MÉDIA IBÉRICA: O LIBRO DEL CONSEJO E DE LOS CONSEJEROS

Douglas Mota Xavier de Lima

Êmily Sthephane Rodrigues

Buescu enfatiza que a "ordem do discurso", a par de sua apreciação como suporte ideológico da monarquia, deve ser vista como lugar de advertência e de estabelecimento dos próprios limites do poder, dimensão que também indiscutivelmente integra. Assim, o caráter normativo dos espelhos de príncipes define espaços e ordena comportamentos nas relações sociais. Esses, por sua vez, ultrapassam a representação de um monarca ideal, mas direcionam a prática do oficio régio (BUESCU, 1997, p. 33-34).

Diante das questões expostas, o presente texto concentra-se no espaço ibérico e procura discutir como o gênero dos espelhos e, especificamente dos espelhos de conselheiro, contribuíu para definir um perfil dos conselheiros de finais da Idade Média. Nesse artigo foi analisada a obra Libro del consejo e de los consejeros, escrita por Maestre Pedro. Partindo dos apontamentos de Buescu e Chartier, tratar-se-á num primeiro momento como, através da "ordem do discurso", expressa aqui pelos espelhos de príncipes, foram delineadas uma imagem ideal de governante e, com a segmentação do gênero, um perfil de conselheiro no período quatrocentista. Para isso, busca-se apresentar, em linhas gerais, o desenvolvimento da pedagogia política no Ocidente medieval.

\section{A pedagogia política no Ocidente medieval e o caso ibérico}

Espelhos de príncipes (miroir au prince, mirror of prince) é o termo utilizado para denominar um conjunto de obras de cunho formativo dirigidas a reis e príncipes, baseadas em doutrinas cristãs e tradições helênicas que estabelecem condutas éticas e morais para a formação de um bom governante. A designação se aplica a textos diversos, escritos em prosa ou em verso, obras breves e longas e de gênero literário variado, como tratados, sermões, entre outros (GENET, 2003).

Espelho, do latim speculu, expressa a reprodução fiel da imagem, representação, reflexo. Em seu sentido figurado, um modelo, exemplo a ser seguido, 


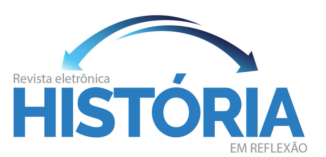

O PERFIL DOS CONSELHEIROS NA BAIXA IDADE MÉDIA IBÉRICA: O LIBRO DEL CONSEJO E DE LOS CONSEJEROS

Douglas Mota Xavier de Lima

Êmily Sthephane Rodrigues

imitado. Deriva do verbo depoente latino speculor, cuja primeira acepção é observar, vinculando-se a tradição veterotestamentária e greco-romana (COSTA, 2004). Em vista desse sentido medieval do termo, observa-se que "espelho" funciona como um topos presente em diferentes textos, podendo designar os livros sagrados, a Bíblia, a vida dos santos e a Revelação, estando assim presente numa série de manuais morais. Diante da flexibilidade dos usos medievais do termo speculu, Einar Jónsson (2006) propõe a existência de quatro gêneros de "espelhos de príncipes" que conheceram uma evolução diacrônica, em especial, a partir dos séculos XII e XIII. Nessa perspectiva, defende que: «Un "miroir au prince" est un traité écrit pour un prince - et en général dédié à lui - qui a pour objet principal de décrire le prince idéal, son comportement, son rôle et sa situation au monde». (JÓNSSON, 2006, p. 5)

Segundo Michel Senellart (2006), o primeiro tratado sobre o governo do príncipe tendo o título de Espelho (Speculum) surgiu no final do século XII: o Speculum regale, de Godofredo de Viterbo (1180/1183). Nessa perspectiva, a produção de tratados sobre o governo se desenvolveu ao longo dos séculos seguintes, podendo citar: Policraticus, de João de Salisbury, no século XII; De Regimine Principum, de Egídio Romano, De regimine principum, de São Tomás de Aquino, Konungs-Skuggsja (Speculum regale), de origem norueguesa, no século XIII; o Speculum regis, de Simon Islip, Speculum regum, do franciscano Álvaro Pais ou Pelágio, e Speculum morale regium, de Robert Gervais, no século XIV; ou ainda Institutio Principis Christiani, de Erasmo e O Príncipe, de Maquiavel, no século XVI.

Em resumo, a tradição literária dos espelhos de príncipes que se afirma no Ocidente medieval baseava-se em doutrinas cristãs e preceitos morais grecoromanos promovendo a imagem exemplar de príncipe, aquele que conduz seu povo à salvação, ressaltando a importância do ofício de bem governar o reino. Portanto, ao monarca, livrar-se dos vícios e apropriar-se de virtudes era vencer a dualidade que reside no homem, causada pela própria natureza do pecado. 


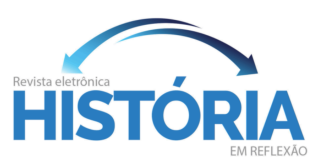

O PERFIL DOS CONSELHEIROS NA BAIXA IDADE MÉDIA IBÉRICA: O LIBRO DEL CONSEJO E DE LOS CONSEJEROS

Douglas Mota Xavier de Lima

Êmily Sthephane Rodrigues

Como foi exposto, o apogeu dos espelhos de príncipe no Ocidente medieval deu-se no século XIII e a Península Ibérica também viu florescer nas cortes régias uma literatura especular. Como demonstram Adeline Rucquoi e Hugo Bizzarri (2005), ao pensar estes textos peninsulares, deve-se levar em consideração a significativa influência de obras do mundo muçulmano, como, por exemplo, Kalila e Dimna, fruto da cultura árabe e ligada à tradição dos espelhos de príncipes ou da literatura sultanesca.

David Rincón (2006), ao tratar desta literatura ibérica, propõe a classificação dos espelhos de acordo com sua procedência, considerando elementos estruturais. Para o autor, os espelhos orientais se preocupam com aspectos éticos e morais, enquanto, os espelhos ocidentais incorporam uma combinação de aspectos éticos e teoria política. Nos fins do século XIII, segundo Rincón, El Libro del consejo e de los consejeros demonstra completo abandono das formas orientais em favor de autores clássicos, como Cícero e Sêneca. Este artigo não aprofundará essa contribuição oriental, mas cabe mencionar a sua importância, pois as formas orientais são preponderantes na produção especular ibérica, por exemplo, em obras como El Libro de los doce Sabios, do século XIII.

Em Portugal, a tradição dos espelhos pode ser exemplificada na obra do já citado franciscano Álvaro Pais, Bispo de Silves, o Speculum regum, do século XIV; no De republica gubernanda per regem, de Diogo Lopes Rebelo; na Breve doutrina e ensinança de príncipes, do Frei António de Beja; na Doutrina de Lourenço de Cáceres ao Infante D. Luís, filho de D João III; e na obra de D. Jerônimo Osório, dedicada a D. Sebastião, Da ensinança e educação do rei, no século XVI (REIS, 2016, p. 239).

Dito isso, considera-se que os espelhos de príncipe acompanharam as transformações ocorridas na Baixa Idade Média, em especial aquelas relacionadas à monarquia e à figura do rei, e a proliferação de espelhos de príncipes em diferentes partes da Cristandade contribuiu como forte instrumento de formação de bons governantes. Nesse cenário, a literatura especular conheceu variações no gênero dos 


\section{HISTÓRIA}

O PERFIL DOS CONSELHEIROS NA BAIXA IDADE MÉDIA IBÉRICA: O LIBRO DEL CONSEJO E DE LOS CONSEJEROS

Douglas Mota Xavier de Lima

Êmily Sthephane Rodrigues

espelhos, entre elas, uma inovação surgida no século XIV, os espelhos de conselheiros.

Espelhos de conselheiros

Ao aprofundar a leitura dos espelhos de príncipes é comum encontrar a repetição nos aspectos da educação régia, o que atribui ao gênero um caráter uniforme. Porém, os estudos de Jacques Krynen (1993) advertem sobre o engano dos pesquisadores em se deixarem levar pela aparência convencional desses tratados políticos. Em síntese, ao observar essas obras é possível notar algumas inovações nas entrelinhas, por exemplo, a ênfase dada a figura do conselheiro nos textos.

Márcio Muniz (2005) argumenta que a "independência" da figura do conselheiro real no arcabouço maior dos espelhos de príncipe acompanhou, histórica e contextualmente, a maior institucionalização do Conselho Régio como um dos órgãos constituidores do aparato governativo. Nesse sentido, além de obras com uma pedagogia voltada para a educação de príncipes e reis, a sociedade medieval no decorrer do século XIII também assistiu à produção de obras voltadas para o Conselho e para os conselheiros. Estes, por sua vez, deveriam ser homens livres de vícios, virtuosos e, inicialmente, vinculados ao saber letrado. Assim:

A consequência imediata disso é uma normativa presente em quase todos os manuais de educação do príncipe dizendo respeito às qualidades que deveriam possuir os conselheiros reais, como escolhêlos, de que grupo social deveriam provir, em que tipo de ação poderiam colaborar ou ser solicitados a aconselhar e, na outra extremidade do mesmo ensinamento, quais os homens a que não correspondia o papel de conselheiro, que tipos de características, ou melhor, de vícios, o rei era aconselhado a evitar em relação àqueles que o ajudariam a governar (MUNIZ, 2005, p. 107). 


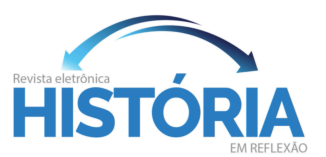

O PERFIL DOS CONSELHEIROS NA BAIXA IDADE MÉDIA IBÉRICA: O LIBRO DEL CONSEJO E DE LOS CONSEJEROS

Douglas Mota Xavier de Lima

Êmily Sthephane Rodrigues

Essa variação do gênero espelhos de príncipes, denominado de espelhos de conselheiros, constitui obras que enfatizam a responsabilidade do monarca no sentido de saber reconhecer e escolher bons conselheiros, além de ensinar o que é ser um bom conselheiro, ofício do qual dependeria o bem conduzir do governo. São exemplos desse subgênero o Libro del Consejo e de los consejeros, de Maestre Pedro, tratado que inaugurou a produção de espelhos de conselheiros no espaço ibérico; o Consejo y Consejeros del Príncipe, de Fadrique Furió Ceriol (1559), dedicado a Filipe II; o Tractado del Consejo y de los Consejeros de los Príncipes, de Bartolomeu Filipe (1584), tratado com 18 discursos sobre o Conselho e os conselheiros; e o Leal Conselheiro, de D. Duarte, endereçado aos homens da Corte, em especial aos seus conselheiros.

Em linhas gerais, o Conselho Régio tem suas origens no século IX, no período carolíngio. Através do ritual feudo-vassálico o vassalo firmava a obrigação de "aconselhar" o senhor sempre que fosse solicitado, devendo deslocar-se até a Corte. Segundo Armando Luís de Carvalho Homem (1987), na Península Ibérica os Conselhos régios assumem diferentes formas em sua organização como aparato governativo e, entre avanços e recuos, no século XIII, tornou-se órgão de assessoramento real. $\mathrm{O}$ autor avança em propor a diferenciação de várias matrizes institucionais: a doméstica, a guerreira e a burocrática, que se desmembraria em judicial e financeira. Carvalho Homem aponta para a inexistência de uma matriz política concretizada no Conselho régio, ligada às atividades dos grandes acontecimentos. Portanto, cabia aos conselheiros tratar de assuntos como: guerra, paz, diplomacia, legislação, provimento de bailios, justiça e qualquer assunto de que fossem encarregados pelo monarca.

Reafirmando a importância do Conselho no universo governativo, Bernard Guenée pontua que, no fim da Idade Média, o Conselho é o motor do Estado. O príncipe continua com sua influência, mas são raros os Conselhos que são apenas 


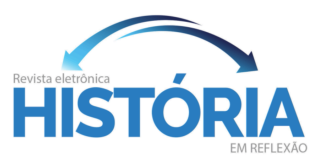

O PERFIL DOS CONSELHEIROS NA BAIXA IDADE MÉDIA IBÉRICA: O LIBRO DEL CONSEJO E DE LOS CONSEJEROS

Douglas Mota Xavier de Lima

Êmily Sthephane Rodrigues

instrumentos na mão do príncipe, sendo o Conselho "órgão flexível e eficaz, e ao mesmo tempo consultivo e executivo" (GUENÉE, 1981, p. 160-161).

Em síntese, os escritos indicam ao rei as qualidades de um bom conselheiro, mostrando também os vícios daqueles que não servem ao Conselho. Diante dos elementos expostos, passa-se a caracterização da obra Libro del Consejo e de los consejeros, de Maestre Pedro, e a discussão sobre o perfil de conselheiro expresso neste espelho ibérico.

\section{O Libro del Consejo e de los consejeros}

O Libro del Consejo e de los consejeros é o primeiro tratado conhecido na Península Ibérica que se dedica ao tema do Conselho e dos conselheiros reais, porém existem ainda muitas interrogações sobre seu autor e sua datação. De acordo com Barry Taylor (2014), a problemática da autoria do Libro del Consejo e de los consejeros consiste na escolha do autor pela terminologia "Yo Maestre Pedro", denominação que impossibilita deduzir mais detalhes da autoria, considerando que, se Maestre Pedro pertencesse à uma ordem religiosa ou militar, o texto indicaria. Para Taylor, ainda que Maestre Pedro demonstre habilidades na exegese bíblica, ou seja, em comentários biblícos, não quer dizer que fosse um clérigo escrevendo, visto que, autores laicos como Pero López de Ayala e Enrique de Villena também utilizavam do conhecimento clerical. Contudo, é impossível saber se o adicional de "maestre" também é uma tentativa de esconder seu autor, deixando a autoria da obra uma questão à ser resolvida pela historiografia.

As tentativas de identificação do autor do Libro del Consejo e de los consejeros não são seguras e não alcançam visibilidade. Entretanto, a tese de Billy R. Weaver, trabalho que classifica Pero Gómez Barroso como autor do Libro del Consejo e do Castigos de Sancho IV é uma exceção e considerada uma atribuição frágil, visto que o Libro del consejo não faz referência a pessoas ou fatos da contemporaneidade. 


\section{HISTÓRIA}

O PERFIL DOS CONSELHEIROS NA BAIXA IDADE MÉDIA IBÉRICA: O LIBRO DEL CONSEJO E DE LOS CONSEJEROS

Douglas Mota Xavier de Lima

Êmily Sthephane Rodrigues

Taylor (2014) argumenta que o Libro utiliza trechos do Manipulus florum de Thomas Hibernicus, uma das fontes mais modernas da obra do Maestre Pedro e que circulou na Universidade de Paris somente a partir de 1306, o que constata que o Libro del consejo não é fruto da corte de Sancho IV (1284-1295).

No rol de textos de teor moralizante, o Libro del Consejo e de los consejeros se aproxima de obras como as de D. Juan Manuel e Sancho IV, produções que sugerem um contato ativo de Maestre Pedro com Paris. Apresentando as relações textuais do Libro com outras obras do período, Taylor sustenta em relação a datação que "Estas consideraciones me llevan a proponer para el Libro del consejo un terminus post quem de 1306 (...) una fecha de composicion entre 1306 y digamos 1336" (TAYLOR, 2014, p.15).

Outro elemento importante na caracterização do Libro del consejo é a língua, esta que parece pertencer ao início do século XIV:

\footnotetext{
Sin entrar en análisis pormenorizados, la lengua del Libro del consejo, según se conserva en el ms.E (Escorial, Z.III4), es análoga al estado de la lengua que presentan las obras de don Juan Manuel en el ms.S (BNE, 6376); es decir, un texto compuesto hacia 1330 y conservado en un testemonio del siglo XV. (Rey 1962, apud Taylor, 2014, p.15)
}

Segundo Taylor (2014), Maestre Pedro baseou-se principalmente no Libro consolationis et consilii de Albertano de Brescia. Este autor foi jurista e escreveu obras como o Liber de amore et dilectione Dei (1238), o Liber de doctrina loquendi et tacendi (1245) e o Liber Consolationis et consilii. Esses tratados são citados no Libro del consejo, sendo o Liber Consolationis et consilii citado com frequência por Maestre Pedro. Entretanto, no campo da literatura ocidental o Liber consolationis et consilii possui poucos antecedentes, existindo então, a possibilidade deste pertencer à tradição oriental de escritos como o Kalila e Dimna.

Conforme o levantamento de Taylor, boa parte de autoridades bíblicas, patrísticas e clássicas do Libro del consejo são citadas por meio da obra de Albertano 


\section{HISTÓRIA}

O PERFIL DOS CONSELHEIROS NA BAIXA IDADE MÉDIA IBÉRICA: O LIBRO DEL CONSEJO E DE LOS CONSEJEROS

Douglas Mota Xavier de Lima

Êmily Sthephane Rodrigues

de Brescia, desde Séneca até escritores de menos trato, como Godofredo de Whinchester. Além disso, obras universais da Idade Média, como a Bíblia e os Disticha Catonis (Catonis Disticha), também são citadas através do Consolationis et consilii. Outras referências presentes em Maestre Pedro são: Alexandreis, de Gautier de Chântillon (1178-82); Prisciano, possivelmente por meio do Florilegium Gallicum; Communiloquium, do fransciscano Juan de Gales; Manipulus Florum, de Thomas Hibernicus, a fonte mais moderna do Libro; fontes castellanas como Bocados de oro, Vida de Segundo, Flores de Filosofia e Castigos de Sancho IV. A obra de Maestre Pedro possui ainda referências não identificadas como citações que são atribuídas a um "sábio Salomão".

Para a presente pesquisa foi utilizada a edição do Libro del Consejo e de los Consejeros de Barry Taylor, curador de estudos hispânicos da British Library e doutor na literatura sapiencial em castelhano, latim e catalão. Publicada em 2014, como primeiro volume da Biblioteca de Literatura Sapiencial da Fundação San Millán de la Cogolla, a edição baseia-se no Ms. A (BNE,ms. 6559), no Ms. C (BNE, ms. 9216) e, sobretudo, no Ms. E (Escorial, ms. Z.m.4), todos datados do século XV. Como citado pelo autor, essa versão não procura reconstruir a edição original de Agapito Rey, limitando-se a corrigir erros, como por exemplo, a oscilação entre singular e plural.

Diante dos elementos expostos, passa-se para a discussão do perfil dos conselheiros expresso pelo Libro del consejo e de los consejeros na perspectiva dos espelhos de conselheiros. No prólogo, capítulo I, Maestre Pedro expõe o que deseja falar:

Dize un sabio que ha nonbre Boecio que quando ome quiere fablar de algunas cosas de saber para fazer algunas obras deve començar en aquello que há de ordenar primeiro. Pues yo, queriendo fablar del consejo e de los consejeros quáles han a ser, este libro toma ende su nonbre e conviéneme començar en este capítulo en que se faze pregunta qué cosa es consejo e quantas son las cosas que convienen (2014, p. 116). 


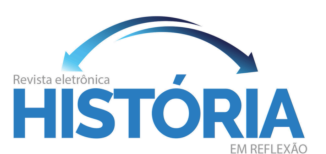

O PERFIL DOS CONSELHEIROS NA BAIXA IDADE MÉDIA IBÉRICA: O LIBRO DEL CONSEJO E DE LOS CONSEJEROS

Douglas Mota Xavier de Lima

Êmily Sthephane Rodrigues

O desenvolvimento da obra se estrutura em torno da oposição entre o bom conselho/conselheiro e o mau conselho/conselheiro, constraste que amplia a didaticidade do texto. Para Maestre Pedro, o conselho é a intenção da vontade do homem verdadeiramente escolhido para ordenar os fatos que são bons, entretanto, os conselhos maus e enganosos são a compreensão da vontade do homem falsamente escolhido. A todo bom conselheiro convém seis coisas: não aconselhar antes de ser chamado; somente aconselhar após conhecer e pensar no assunto; debater com os outros conselheiros; conhecer a quem vai aconselhar; manter em sigilo as deliberações do Conselho; por último, mas não menos importante, o conselheiro deve buscar a honra daquele a quem aconselha (2014, p. 177-118).

Apoiando-se no que diz Albertano de Brescia, Maestre Pedro aponta seis qualidades que convém ao conselheiro: que sejam homens de boa vida, bem acostumados e de vida santa; homens sábios e bem entendidos; anciãos, pois já passaram por muitas coisas; firmes e estáveis, para que não operem pelo temor nem pelo amor, nem por cobiça, perseverando no caminho da justiça de Deus; que sejam amigos verdadeiros daqueles a quem aconselham e que aconselhem verdadeiramente; e, por último, os conselheiros devem ser postos à prova (2014, p. 130-137).

No capítulo VII, a preocupação com a moral reverbera, apresentando os vícios que são contrários a todos aqueles que são conselheiros. A ira, a cobiça e o arrebatamento do coração representam as más vontades e tudo que pode nascer destas, resultando em seis coisas: o agir com loucura e baixeza; o ser lisonjeiro; a cegueira de entendimento; o ser que causa inimizade, aquele que desata laços; atitudes que diminuem a vida do homem; e, por fim, a maldade, fruto da ira e da cobiça (2014, p. 138-141).

Em linhas gerais, os vícios que embargam o ser conselheiro são: a ira (VII); a cobiça, (VIII); o arrebatamento do coração (IX); a falta de temperança, tanto no modo 


\title{
HISTÓRIA
}

O PERFIL DOS CONSELHEIROS NA BAIXA IDADE MÉDIA IBÉRICA: O LIBRO DEL CONSEJO E DE LOS CONSEJEROS

Douglas Mota Xavier de Lima

Êmily Sthephane Rodrigues

de agir quanto do falar (X); a torpeza e a loucura (XI); o lisonjeador (XII); as inimizades (XIII); o amor oriundo do temor (XIV); a embriaguez (XV); homem de duas línguas, os "bislinguis" (XVI); a maldade (XVII); e, finalmente, a juventude (XVIII).

O capítulo XIX trata das premissas que devem ser respeitadas entre 0 conselheiro e aquele que recebe o conselho, reafirmando os requisitos do conselheiro perfeito e a importância do Conselho como aparato governativo:

\begin{abstract}
E las cosas que fazen a la prueva del consejo son seis: la primera cosa que conviene a todo leal consejero sí es escodriñar con grand pensamiento de coraçón todas las cosas que pueden acaescer en el fecho del consejo. La segunda, que deve escojer lo que le fuere más provecho para dar buen consejo. La terceira, ordenar los comienços del consejo en todo lo que se ha a dezir e a fazer en ellos. La quarta, catar que aya verdat en todas las cosas que son razonadas en el consejo. La quinta, que deven acordar las razones que fazen al consejo. (...) La sexta razón es que deve guardar las razones de las cosas que tañen al fecho del consejo que lo que se faze com razón es bueno e provechoso e lo ál non es duradero nin estable nin pertenesce a los omes. (2014, p. 195-196).
\end{abstract}

Sendo o conselheiro uma figura relevante na governação e de crescente importância na Baixa Idade Média, a tradição especular passa a considerar com maior autonomia e detalhamentos o que se espera do aconselhamento e daqueles que proferem conselhos. Inserindo-se nesse movimento, Maestre Pedro constrói um tratado didático que define as virtudes necessárias para o aconselhamento, prerrogativas que, se não observadas, podem levar o reino a consequências negativas, com os males que nascem de cada vício presente nos maus conselhos/conselheiros.

Ao esquematizar como deve ser o aconselhamento, Maestre Pedro desenha um perfil ideal para o ato de aconselhar, para os conselheiros e para a instância do Conselho. O autor se propõe a delinear um perfil virtuoso para os conselheiros, reafirmando no âmbito do aconselhamento as virtudes cristãs. Seu modelo procura orientar a formação e a experiências do conselheiro, indicando a relevância da 


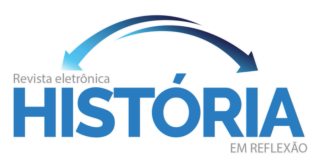

O PERFIL DOS CONSELHEIROS NA BAIXA IDADE MÉDIA IBÉRICA: O LIBRO DEL CONSEJO E DE LOS CONSEJEROS

Douglas Mota Xavier de Lima

Êmily Sthephane Rodrigues

sabedoria e do conhecimento; educar o corpo, através da fala, dos gestos e dos comportamentos adequados; e instruir a alma, demonstrando que o conselheiro ideal deve levar uma vida santa e atenta aos preceitos morais do bom cristão. Nota-se, no entanto, que Maestre Pedro oferece maior ênfase aos vícios que devem ser identificados e evitados, do que às virtudes esperadas dos conselheiros. Deste modo, ao passo que exorta os homens que procuram ocupar tal lugar de destaque ao lado dos monarcas, o autor orienta o próprio rei no processo de escolha de seus conselheiros e de avaliação dos conselhos recebidos.

Em seu texto, Maestre Pedro mobiliza tópos do pensamento greco-romano acerca do aconselhamento, como a importância da amizade. No Ocidente medieval, a obra De Amicitia, de Cícero, foi a principal referência da noção de amizade, estabelecendo a relação entre a amizade, a natureza e a virtude, demonstrando que a amizade só pode existir entre os bons (GUIMARÃES, 2011). Cícero não explorou o papel da amizade na orientação da vida prática e funcional dos homens, mas o Libro del consejo utiliza-se desses referenciais para estabelecer um conselheiro ideal que preza pela amizade, fruto da vida virtuosa, garantindo o correto serviço ao reino e ao monarca.

Todavia, além de mobilizar os referenciais clássicos, Maestre Pedro mostra-se atento aos problemas prementes de seu tempo, como a circulação de informações e a necessidade do sigilo (JUCKER, 2006). Como demonstrado, o Conselho régio afirmou-se desde a Baixa Idade Média como uma das principais instâncias da governação, sendo um espaço de aconselhamento e de discussão das principais questões dos reinos. Se, por um lado, a legislação reafirmava as duras penas previstas para a prática da espionagem e para os crimes de lesa-majestade, a educação moral, exemplificada pela obra de Maestre Pedro, orientava que os conselheiros deveriam "manter em sigilo as deliberações do Conselho".

O Libro del consejo trabalha a construção do perfil do conselheiro no contraste entre e vícios e virtudes, prática comum na tradição especular. Maestre Pedro destaca 


\section{HISTÓRIA}

O PERFIL DOS CONSELHEIROS NA BAIXA IDADE MÉDIA IBÉRICA: O LIBRO DEL CONSEJO E DE LOS CONSEJEROS

Douglas Mota Xavier de Lima

Êmily Sthephane Rodrigues

um perfil que não só está ligado ao lugar de onde devem vir estes homens como a uma doutrina de condutas a serem respeitadas para a consolidação política do reino, elementos que são garantidores da paz e da justiça. Segundo Muniz, "nos séculos seguintes, voltamos a encontrar obras, produzidas por pensadores ibéricos, dedicadas exclusivamente aos tema do Conselho e dos conselheiros, a comprovar a longa duração da tradição inaugurada pelo pequeno tratado de Maestre Pedro" (2005, p. 114).

\section{Considerações finais}

Qual o perfil dos homens que aconselhavam os monarcas ocidentais ao final da Idade Média? A pergunta que estrutura a presente reflexão é ampla e envolve elementos como idade, inserção social, origem geográfica, formação e as concepções sobre a prática do aconselhamento. Concentrando as atenções nesse último fator, o texto procurou demonstrar como os conselheiros e o próprio ato de aconselhar foram temáticas que se afirmaram desde o século XIV.

Primeiramente, foi elaborado um panorama do gênero dos espelhos no Ocidente medieval, enfatizando suas raízes na Antiguidade Clássica até o século XIII, período áureo da produção dos espelhos, demonstrando a importância da produção especular para a construção de um perfil de príncipes e reis.

No segundo momento, situou-se a produção dos espelhos no espaço ibérico, exemplificando espelhos e seus tópicos repetitivos, característica que contribuiu para o afastamento de pesquisadores do gênero. Após a ampliação dos eixos de pesquisas impulsionada, por exemplo, pela terceira geração dos Annales, os espelhos de príncipes foram vistos com novos olhares pela historiografia, a qual destacou que, no início do século XIV, o gênero dos espelhos viu nascer um subgênero, os espelhos de conselheiros. 


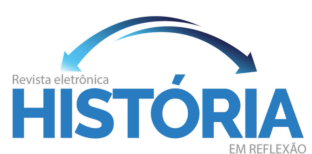

O PERFIL DOS CONSELHEIROS NA BAIXA IDADE MÉDIA IBÉRICA: O LIBRO DEL CONSEJO E DE LOS CONSEJEROS

Douglas Mota Xavier de Lima

Êmily Sthephane Rodrigues

Em seguida, tratou-se dos espelhos de conselheiro, que evidenciam a figura do conselheiro real, sendo o referido subgênero inaugurado no espaço ibérico por Maestre Pedro com o Libro del Consejo e de los Consejeros, essencial para a compreensão do perfil do conselheiro. Além disso, buscou-se situar as origens do Conselho régio, problemáticas relativas a instância, sua importância e o caminho para pesquisar as atribuições do Conselho e sua atuação. Exemplificou-se alguns espelhos de conselheiros na Península Ibérica e tópicos que caracterizam o bom conselheiro, como por exemplo: o melhor conselheiro é aquele que é amigo de seu rei.

Paralelamente à discussão sobre o Conselho, procurou-se demonstrar que a própria realeza vivenciou uma série de transformações na Baixa Idade Média e tais mudanças se expressam na literatura especular. Ainda nesta etapa, tratou-se da caracterização do perfil dos conselheiros e do Conselho régio na obra de Maestre Pedro, tratado que inaugura a produção de espelhos de conselheiros na Península Ibérica. Após a descrição da parte estrutural da obra (contexto, língua, aparato crítico, fontes, autoria e outros), passou-se a discussão do eixo de vícios e virtudes da obra, enfatizando os males que nascem do conselheiro que possui vícios.

A análise do Libro del Consejo e de los consejeros de Maestre Pedro evidencia que o texto cria um padrão de comportamentos aos conselheiros, estabelecendo condutas corretas e inadequadas a tais homens. No Conselho régio, as virtudes contribuem para o êxito das tarefas e, por conseguinte, colaboram para o bom governo. Em contrapartida, saber identificar os vícios que impedem um homem de ser do Conselho é um dever do rei, função que reafirma a importância dos espelhos de conselheiros para a boa governação do reino.

Deste modo, observa-se a relevância da instância do Conselho, dos homens que ocupam tais posições e da prática do aconselhamento no pensamento político de finais do medievo. Tais questões tornam-se centrais na tradição especular que passa a se ramificar no subgênero espelho de conselheiros, que foi inaugurado no espaço ibérico pela obra de Maestre Pedro, e expressa a necessidade de orientar através de 


\section{HISTÓRIA}

O PERFIL DOS CONSELHEIROS NA BAIXA IDADE MÉDIA IBÉRICA: O LIBRO DEL CONSEJO E DE LOS CONSEJEROS

Douglas Mota Xavier de Lima

Êmily Sthephane Rodrigues

um discurso moralizador e pedagógico a prática desses homens da burocracia régia e, em especial, homens da corte régia, que cada vez mais, com os seus conselhos, definiam os rumos das monarquias ocidentais.

Referências Bibliográficas

Fonte

PEDRO, Maestre. Libro del consejo e de los consejeros. Edición de Barry Taylor. San Millán de la Cogolla: Cilengua, 2014.

Bibliografia

BUESCU, Ana Isabel. Um discurso sobre o príncipe. A "pedagogia especular" em Portugal no século XVI. Penélope, 17, 1997, pp. 33-50.

CHARTIER, Roger. Construção do Estado moderno e formas culturais. Perspectivas e questões. In: A História Cultural: entre práticas e representações. Lisboa: Difel, 2002, p.215-229.

COSTA, Ricardo da. O espelho de Reis (1341-1344), do galego Álvaro Pais. In: MALEVAL, Maria do Amparo Tavares (org.). Estudos galegos 4. Niterói: EdUFF, 2004, p.185-198.

GENET, Jean-Philippe. L'évolution du genre des Miroirs des princes en Occident au Moyen Âge. In: CASSAGNES-BROUQUET, Sophie et al. (dir.). Religion et mentalités au Moyen Âge: Mélanges en I'honneur d'Hervé Martin. Nouvelle édition [en ligne]. Rennes: Presses Universitaires de Rennes, 2003.

GUENÉE, Bernard. O Ocidente nos séculos XIV e XV - Os Estados. São Paulo: Pioneira, Editora da Universidade de São Paulo, 1981.

GUIMARÃES, Marcella Lopes. De Cícero a Fernão Lopes, considerações sobre a amizade do Ocidente Medieval. Convergência Lusíada, n.26, julho-dezembro de 2011. 


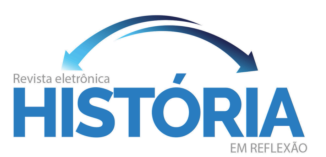

O PERFIL DOS CONSELHEIROS NA BAIXA IDADE MÉDIA IBÉRICA: O LIBRO DEL CONSEJO E DE LOS CONSEJEROS

Douglas Mota Xavier de Lima

Êmily Sthephane Rodrigues

HOMEM, Armando Luís de Carvalho. Conselho Real ou conselheiros do Rei? a propósito dos "privados" de D. João I. Revista da Faculdade de Letras, História, n.4, 1987, p.9-68.

JÓNSSON, Einar Már. Les "mirroirs aux princes" sont-ils un genre littéraire? Médiévales, Langues, Textes, Histoire [en ligne], 51, automne 2006, pp.1-11.

JUCKER, Michael. Secrets and Politics: methodological and communicational aspects of late medieval diplomacy. II Segreto, Micrologus, 14, 2006, p. 1-35.

KRYNEN, Jacques. L'Empire du roi. Idées et croyances politiques en France. XIIleXve siècle. Paris: Gallimard, 1993.

LIMA, Douglas Mota Xavier de. A Diplomacia portuguesa no reinado de $\mathbf{D}$. Afonso V (1448-1481). Niterói: Universidade Federal Fluminense, tese de doutorado, 2016.

MICHON, Cédric. Essai de synthèse. Conseils et conseillers en Europe occidentale (v. 1450-v.1550). In: MICHON, Cédric (dir.). Conseils et Conseillers dans I'Europe de la Renaissance (v.1450-v.1550). Rennes: Presses Universitaires de Rennes, 2012, p.341-412.

MUNIZ, Márcio Ricardo Coelho. Espelho de conselheiros: um possível gênero da literatura política ibérica. Floema, ano 1, n.2, p.101-134, dez. 2005.

. O Leal Conselheiro, de Dom Duarte, e a tradição

dos espelhos de príncipe. São Paulo: Universidade de São Paulo, tese doutorado, 2003.

NIETO SORIA, José Manuel. Apología y propaganda de la realeza en los cancioneros castellanos del siglo XV. Diseño literário de un modelo político. En la Edad Medieval, n.11, 1988, p.185-221.

OLIVEIRA, Fabiana. A educação do infante ao príncipe nas obras de Ramon Llull: Caminhos da formação pedagógico-cristã no século XIII. Revista Signum, 2016, Vol.17, n.1, 2016, p.161-177.

PÉQUIGNOT, Stéphane. Les ambassadeurs dans les miroirs des princes en Occident au Moyen Âge. In: ANDRETTA, Stefano; PÉQUIGNOT, Stéphane; WAQUET, Jean- 


\section{HISTÓRIA}

O PERFIL DOS CONSELHEIROS NA BAIXA IDADE MÉDIA IBÉRICA: O LIBRO DEL CONSEJO E DE LOS CONSEJEROS

Douglas Mota Xavier de Lima

Êmily Sthephane Rodrigues

Claude (org.). De l'ambassadeur - Les écrits relatifs à l'ambassadeur et à l'art de négocier du Moyen Âge au debut du XIXe siècle. Roma: École Française de Roma, p.33-55.

REIS, Flávio Antônio Fernandes. Speculum principum: considerações sobre o gênero nas letras portuguesas dos séculos XV e XVI. Revista Signum, 2016, Vol.17, n.1, Sp.235-249.

RINCÓN, David Nogales. Los espejos de príncipes en Castilla (siglos XIII-XV): un modelo literario de la realeza bajomedieval. Medievalismo, n.16, 2006, p.9-39.

RUCQUOI, Adeline; BIZZARRI, Hugo O. Los Espejos de Príncipes en Castilla: entre Oriente y Occidente. Cuadernos de historia de España, Buenos Aires, v. 79, p.7-30, 2005.

SANTOS, Maria Alice Pereira. A sociologia da representação político-diplomática no Portugal de D. João I. Tese de doutoramento em História Medieval. Lisboa: Universidade Aberta de Lisboa, 2015.

SENELLART, Michel. As Artes de governar: do regimen medieval ao conceito de governo. São Paulo: Ed.34, 2006.

TAYLOR, Barry. Introdución. In: PEDRO, Maestre. Libro del consejo e de los consejeros. Edición de Barry Taylor. San Millán de la Cogolla: Cilengua, 2014, p.11103.

VAQUERO, Eloísa Ramírez. Estrategias diplomáticas del rey de Navarra en el trânsito al siglo XV. In: XXI Semana de Estudios Medievales. Guerra y Diplomacia en la Europa Occidental 1280-1480. Navarra: Gobierno de Navarra, 2005. 